\title{
Acute Septic Arthritis Following Supra-Patellar Nailing of an Open Diaphyseal Tibia Fracture in an Immune Compromised Patient
}

\author{
L Henry Goodnough ${ }^{1,2 *}$, Kimberley E Hall ${ }^{1,2}$, Jeffrey E Krygier ${ }^{1,2}$ and Curt P Comstock ${ }^{1,2}$ \\ ${ }^{1}$ Department of Orthopedic Surgery, Stanford Hospitals and Clinics, USA \\ ${ }^{2}$ Department of Orthopedic Surgery, Santa Clara Valley Medical Center, USA
}

*Corresponding author: L Henry Goodnough, MD/PHD, Department of Orthopedic Surgery, Stanford Hospitals and Clinics, 300 Pasteur Drive Room R144, Stanford, CA 94305, USA, Tel: 7164789883; E-mail: henryg@ stanford.edu

\begin{abstract}
The supra-patellar approach represents one approach to intramedullary nailing (IMN) of diaphyseal tibia fractures. Violation of the knee joint utilizing an intra-articular start point represents a risk for septic arthritis of the knee in the post-operative period. Previous retrospective studies of open tibia and femur fractures demonstrated that post-operative knee sepsis is rare, occurs in the chronic phase after injury, and due to extent of soft tissue injury rather than immune compromise. Here, we review current literature on post-operative knee sepsis, and present a case of acute septic arthritis of the knee following supra-patellar nailing of an open tibia fracture in a patient on chronic immune suppression. In this unique case, co-morbid patient factors likely led to this manifestation of a rare complication.
\end{abstract}

Keywords: Septic arthritis; Semi-extended; Supra-patellar; Tibia; Intramedullary nail; Knee sepsis

Received Date: August 16, 2018; Accepted Date: August 28, 2018; Published Date: September 05, 2018

\section{Introduction}

Intramedullary nailing (IMN) of tibia fractures via a semi-extended, supra-patellar approach was initially described for proximal tibia fractures [1], and indications have further broadened to include nearly any morphology diaphyseal tibia fracture given easy fluoroscopy and reduction, and even improved radiologic outcomes [2]. Moreover, the proposed risks of violating the knee joint, which include damage to articular cartilage or meniscus, have been invalidated in published studies. Septic arthritis of the knee represents a potentially devastating complication associated with a trans-articular start point which is rare [3-10]. The few published instances of knee sepsis after retrograde femoral nailing or antegrade tibial nailing occurred in the setting of exceptional soft tissue compromise (Table 1). However, patient factors such as smoking and diabetes are risk factors for deep infection after open tibia fractures [11]. We present here a case of acute septic arthritis of a knee following intramedullary nailing of an open tibia shaft fracture via a supra-patellar approach in a patient on chronic immunosuppression.

Citation: L Henry Goodnough, Acute Septic Arthritis Following Supra-patellar Nailing of an Open diaphyseal Tibia Fracture in an Immune Compromised Patient. J Clin Cases Rep 1(3): 130-134. DOI: https://doi.org/10.46619/joccr.2018.1-1027 


\section{Case History}

The patient is a 49-year-old male with a history of rheumatoid arthritis on prednisone ( $5 \mathrm{mg}$ daily) and methotrexate, type II diabetes mellitus (HbA1c 5.9), and a former smoker, who presented to our hospital after a low energy fall stepping out of his truck, with a Type II open left distal diaphyseal tibia fracture (Figure 1). He had a $5 \mathrm{~cm}$ traumatic wound over the medial aspect of his distal left tibia. After receiving antibiotics in the emergency department, he underwent irrigation and debridement of his open tibia fracture, and intramedullary nailing via a semi-extended supra-patellar approach (Figure 2).

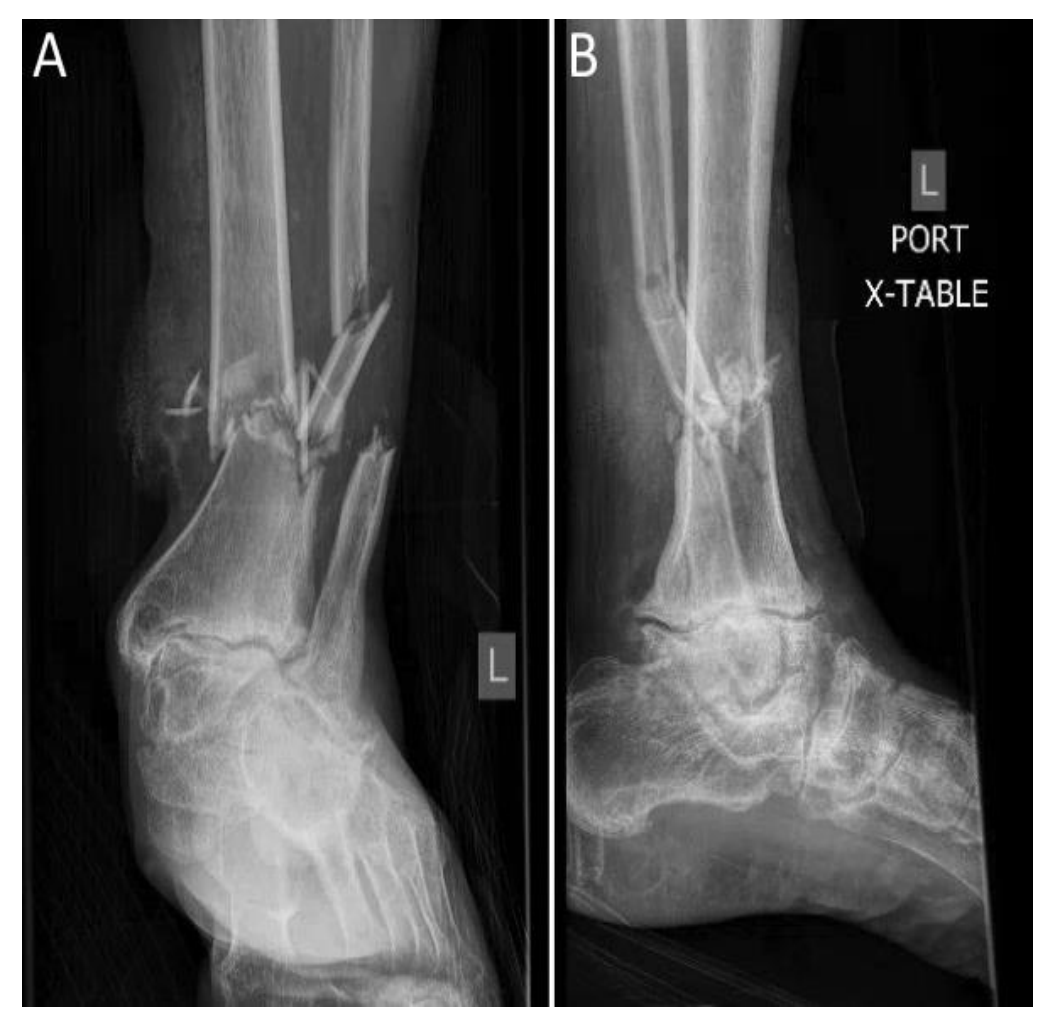

Figure 1: Plain AP (A) and lateral injury radiographs (B).

Intraoperative and post-operative course were unremarkable. On post-operative day 13, he presented to an outside hospital with acute knee pain, erythema, swelling, febrile to $38.3^{\circ} \mathrm{C}$, tachycardic, with a white blood cell count of 14.8 . His erythrocyte sedimentation rate was 95 , and C-Reactive protein was $37 \mathrm{mg} / \mathrm{dl}$, and he received intravenous antibiotics (vancomycin). He was transferred to our emergency department, where aspiration of his knee yielded purulent fluid with 83,622 nucleated cells and $94.5 \%$ neutrophil predominance. He was taken emergently for irrigation and debridement of his left knee in the operating room. Intra-operative findings were remarkable for gross purulence in the knee joint. Notably, his traumatic tibia lacerations were without evidence of infection. No attempt was made to aspirate the nail tract or fracture site. His arthrocentesis and intraoperative cultures yielded no growth with a negative gram stain, and his bacterial sequencing results were negative (bacterial 16S rRNA sequencing [12]), although he had received antibiotics at an outside hospital prior to transfer.

His post-operative course was complicated by acute kidney injury, fever, and rash after ceftriaxone/vancomycin/rifampin therapy. He was discharged on intravenous daptomycin and rifampin. He completed 6 weeks of parenteral daptomycin, and was transitioned to a course of oral doxycycline to be completed at 6 months from surgery. At last follow up he was healing well 6 months from initial injury without evidence of recurrent infection (Figure 3). 

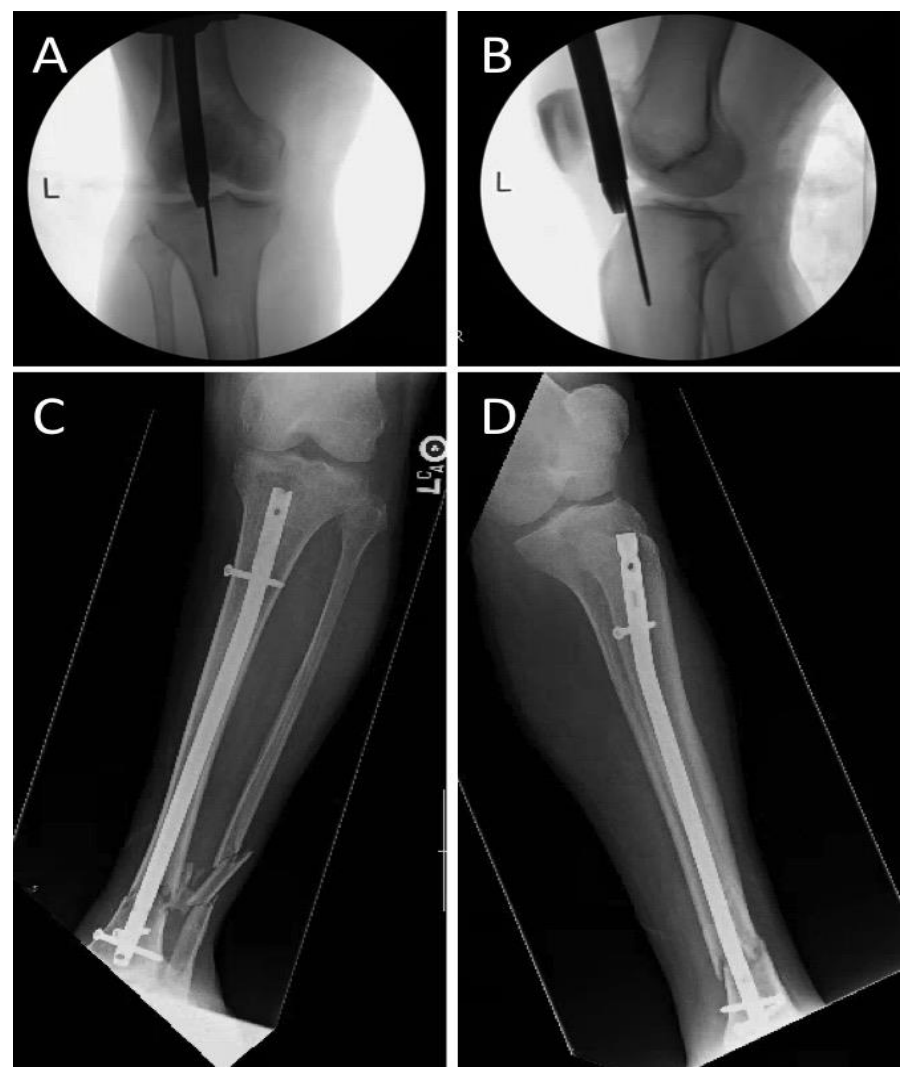

Figure 2: Intraoperative fluoroscopy with AP (A) and lateral (B) views of knee demonstrating starting point for intramedullary nail achieved using suprapatellar approach. AP (C) and lateral (D) X-rays of tibia after intramedullary nailing.
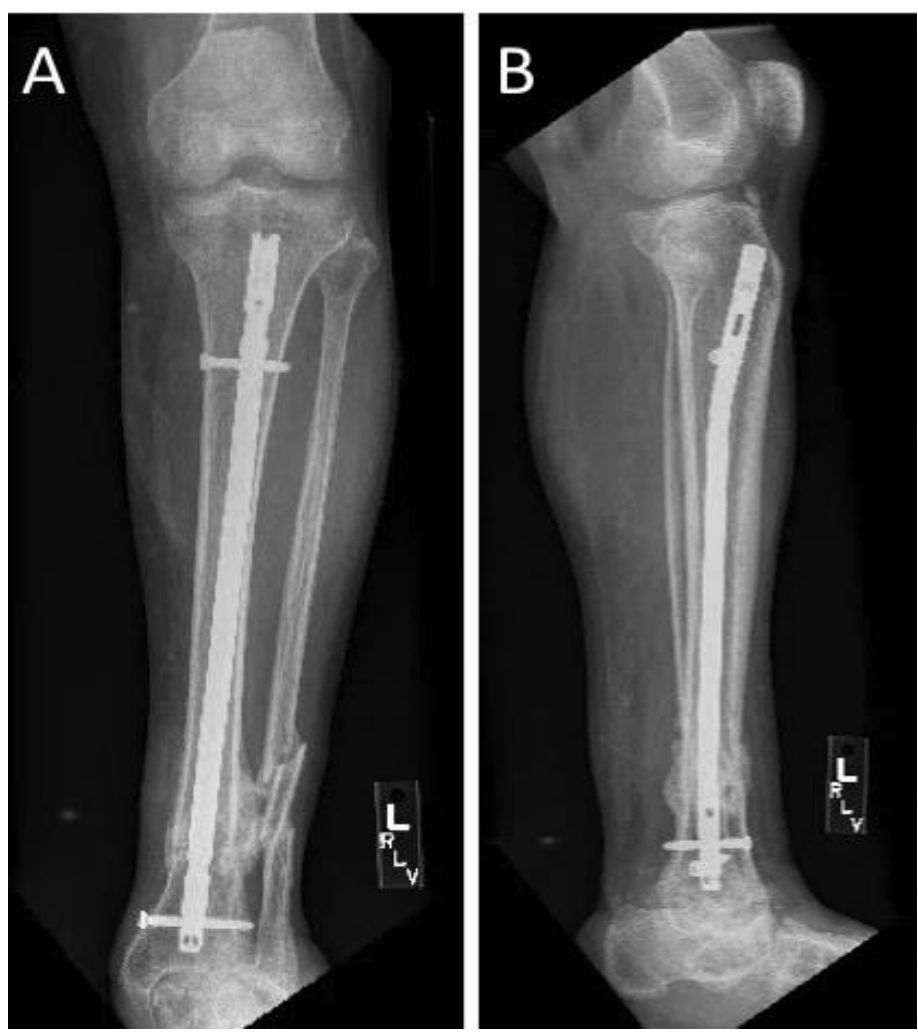

Figure 3: AP (A) and lateral (B) X-rays demonstrating callus formation and interval healing six months after initial surgery.

\section{Discussion}


www.tridhascholars.org | October-2018

We present here an instance of acute septic arthritis of the knee following index supra-patellar IMN of a Type II open tibia fracture in a patient with rheumatoid arthritis on chronic immune suppression, history of tobacco use, as well as diabetes. In our review of current literature, three instances of knee sepsis following medullary nailing of femur or tibia fractures have been reported (Table 1). The contributing factor in each case was extensive soft tissue compromise about the knee with need for multiple debridements, and each instance presented in either subacute to chronic temporal fashion one to four months after injury.

\begin{tabular}{|c|c|c|c|c|c|c|}
\hline Study & $\begin{array}{c}\text { Fractures } \\
\text { (n) }\end{array}$ & $\begin{array}{c}\text { Open (n; } \\
\%)\end{array}$ & $\begin{array}{c}\text { Septic } \\
\text { Arthritis } \\
(\mathbf{n} ; \%)\end{array}$ & $\begin{array}{c}\text { Deep } \\
\text { Infection } \\
(\mathbf{n} ; \%)\end{array}$ & $\begin{array}{l}\text { Patient Risk } \\
\text { Factors for } \\
\text { infection (n; } \\
\% \text { ) }\end{array}$ & Case Notes \\
\hline \multicolumn{7}{|c|}{ Suprapatellar Tibia } \\
\hline Mitchell [3] & 139 & $139(100 \%)$ & $0(0 \%)$ & $25(18 \%)$ & $\begin{array}{l}60(45 \% \\
\text { tobacco, } \\
\text { diabetes })\end{array}$ & $\begin{array}{c}\text { Delayed sepsis } 4 \text { months } \\
\text { post op with necrotizing } \\
\text { infection }\end{array}$ \\
\hline Chan & 11 & $15 / 37(41 \%)$ & $0(0 \%)$ & $0(0 \%)$ & $\mathrm{N} / \mathrm{R}$ & \\
\hline \multirow[b]{2}{*}{ Marecek [6] } & \multirow[b]{2}{*}{147} & \multirow[b]{2}{*}{$147(100 \%)$} & \multirow[b]{2}{*}{$2(1 \%)$} & \multirow[b]{2}{*}{$16(11 \%)$} & \multirow[b]{2}{*}{$\begin{array}{l}44(30 \% \\
\text { tobacco) }\end{array}$} & $\begin{array}{l}-3.5 \text { months after injury, } \\
\text { setting of deep infection and } \\
\text { exchange nail at } 2.5 \text { months }\end{array}$ \\
\hline & & & & & & $\begin{array}{l}\text { - } 5 \text { weeks after injury, } \\
\text { history delayed } \\
\text { presentation, wound } \\
\text { required serial debridements } \\
\text { and complex wound closure }\end{array}$ \\
\hline \multicolumn{7}{|c|}{ Retrograde Femur } \\
\hline Halvorson [4] & 185 & $38(21 \%)$ & 0 & $9(5 \%)$ & N/A & \\
\hline O'Toole [5] & 93 & $100 \%$ & $1(1 \%)$ & $4(4 \%)$ & $\begin{array}{l}30(33 \% \\
\text { diabetes/ } \\
\text { smoker })\end{array}$ & $\begin{array}{c}\text { Concomitant massive } \\
\text { degloving injury with serial } \\
\text { debridements }\end{array}$ \\
\hline Becher [8] & 35 & $100 \%$ & $0(0 \%)$ & $2(6 \%)$ & N/A & \\
\hline Dougherty [9] & 53 & $0 \%$ & $0(0)$ & $1(0.2 \%)$ & N/A & Ballistic injuries \\
\hline Papadokostakis[10] & 573 & $55(10 \%)$ & $1(0.2 \%)$ & $1 \%$ & N/A & \\
\hline
\end{tabular}

Table 1: Review of previous studies examining rates of knee sepsis after suprapatellar nailing if tibia fractures or retrograde nailing of femur fractures. Number of fractures studied, number of open fractures, cases of septic arthritis and deep infection are reported, as well as number of cases with immune compromise. N/A, not applicable: authors did not report smoking/diabetes rates. Case notes for reported instances of knee sepsis demonstrating extensive soft tissue compromise.

In addition to the risk of infection conferred by open fracture, co-morbid risk factors could also increase patient susceptibility to infection [11]. Indeed, our patient not only had poorly controlled diabetes, but was also on long time chronic immune suppression (prednisone) for rheumatoid arthritis and had a history of tobacco use. In our review of previous studies, several series evaluated the presence of smoking and diabetes to infection but did not establish a connection with knee sepsis postoperatively. While previous cases occurred in the chronic phase after injury and multiple surgical debridements, the immune compromise status of this patient likely led to the rapid progression of symptoms one week from injury in this instance. 
www.tridhascholars.org | October-2018

We present here a case of acute septic arthritis following suprapatellar nailing of an open tibia fracture in an immune compromised patient. Compared to rare instances of delayed knee sepsis after extensive surrounding soft tissue injury, this represents a unique case. It is likely that an immune compromised host with an open fracture is more susceptible to postoperative sepsis. We recommend considering an extra-articular start point, if possible, when multiple immune suppressive factors are present. Finally, as the suprapatellar approach for intramedullary nailing is increasingly utilized for its benefits, potential complications should be monitored as well.

\section{References}

1. Tornetta P, Collins E (1996) Semiextended position of intramedullary nailing of the proximal tibia. Clinical Orthopaedics and Related Research 328: 185-189.

2. Jones M, Parry M, Whitehouse M, et al. (2014) Radiologic outcome and patient-reported function after intramedullary nailing: a comparison of the retropatellar and infrapatellar approach. Journal of Orthopedic Trauma 28(5): 256-262.

3. Mitchell PM, Weisenthal BM, Collinge CA (2017) No incidence of postoperative knee sepsis with suprapatellar nailing of open tibia fractures. Journal of Orthopedic Trauma 31: 85-89.

4. Halvorson JJ, Barnett M, Jackson B, et al. (2012) Risk of septic knee following retrograde intramedullary nailing of open and closed femur fractures. Journal of Orthopedic Surgery and Research 7: 7.

5. O'Toole RV, Riche K, Cannada LK, et al. (2010) Analysis of postoperative knee sepsis after retrograde nail insertion of open femoral shaft fractures. Journal of Orthopedic Trauma 24(11): 677-682.

6. Marecek GS, Nicholson LT, Broghammer FH, et al. (2017) Risk of knee sepsis following treatment of open tibia fractures: a multicenter comparison of suprapatellar and infrapatellar approaches. Journal of Orthopedic Trauma 32(2): 82-92.

7. Chan DS, Serrano-Riera R, Grif R, et al. (2016) Suprapatellar versus infrapatellar tibial nail insertion: A prospective randomized control pilot study. Journal of Orthopedic Trauma 30(3): 130-134.

8. Becher S, Ziran B (2012) Retrograde intramedullary nailing of open femoral shaft fractures: A retrospective case series. The Journal of Trauma and Acute Care Surgery 72: 696-698.

9. Dougherty PJ, Gherebeh P, Zekaj M, et al. (2013) Retrograde versus antegrade intramedullary nailing of gunshot diaphyseal femur fractures. Clinical Orthopaedics and Related Research 471(12): 3974-3980.

10. Papadokostakis G, Papakostidis C, Dimitriou R, et al. (2005) The role and efficacy of retrograding nailing for the treatment of diaphyseal and distal femoral fractures: A systematic review of the literature. Injury 36: 813-822.

11. Kortram K, Bezstarosti H, Metsemakers W-J, et al (2017) Risk factors for infectious complications after open fractures; A systematic review and meta-analysis. International Orthopedics 41(10): 1965-1982.

12. Janda JM, Abbott SL (2007) 16S rRNA Gene sequencing for bacterial identification in the diagnostic laboratory: Pluses, perils, and pitfalls. Journal of Clinical Microbiology 45: 2761-2764. 